\title{
Strength characteristics of concrete exposed to the elevated temperatures according to the temperature-time curve ISO 834
}

\author{
Iva Rozsypalová ${ }^{1, *}$, Petr Daněk ${ }^{1}$, Hana Šimonová ${ }^{1}$ and Zbyněk Keršner ${ }^{1}$ \\ ${ }^{1}$ Brno University of Technology, Faculty of Civil Engineering, Veveři 331/95, 60200 \\ Brno, Czech Republic
}

\begin{abstract}
While exposed to high temperatures caused by fire, the concrete undergoes a sequence of physical and chemical structure changes causing a mechanical degradation. This paper concerns an experimental strength determination of a temperature stressed concrete. The concrete was temperature loaded according to temperature-time curve ISO 834 and left on a top temperature level for 60 minutes afterwards. This temperature heating rise is in accordance with a common fire expansion in a structure. The concrete panels sized $150 \times 1300 \times 2300 \mathrm{~mm}$ were temperature loaded up to $550,600,800$ a $1000{ }^{\circ} \mathrm{C}$ in a horizontal position in gas furnace for fire testing of structure elements in research Centre AdMaS. The temperatures of the gas in the furnace and the panel was measured during the whole experiment by using the thermocouples. After the fire test, the specimens were drilled out using a $100 \mathrm{~mm}$ diameter core drill. The compressive strength and splitting tensile strength tests were made and the results were compared to the reference specimen's test results. The objective results of a commonly used strength class concrete loaded by elevated temperature corresponding to the real fire exposure differ common linear heat exposure test results and are considered being very valuable.
\end{abstract}

\section{Introduction}

The fire means a serious danger for the structure safety. Thanks to the fire safety precautions, the significant number of fire accidents is prevented and the consequences concerning loss of lives and property are minimized.

According to EN 1990:2002 [1] the fire related stress is classified as an extraordinary load condition. While designing the structure the fire load and a usual mechanical load is concerned [2].

Despite all the precautions it is still very difficult to prevent many of the fire occurrences and it is necessary to assess the amount of damage and the real condition of a fire-hit structure. Many research teams have been interesting in the fire-stressed concrete

\footnotetext{
${ }^{*}$ Corresponding author: iva.rozsypalova@,vutbr.cz
} 
behaviour and the general opinion considers both compressive and splitting tensile strength decrease after the fire exposure [3,4].

The residual strength characteristics after the high temperature exposure depend on several factors. Using a siliceous aggregate generally leads to a lower residual strength compared to a calcareous aggregate usage. However, the statement is valid only up to approximately $700{ }^{\circ} \mathrm{C}$. Above this temperature, the residual strength differences are minimized. The main differences were observed depending on the cooling process. The fast water based temperature drop caused up to $40 \%$ lower residual strength compared to the slow and spontaneous cooling [3].

The experiments evaluating the concrete characteristics during or after high temperature exposure are based on the gentle temperature increase in general, after that the maximum temperature is maintained for a specified time. The heating is usually performed in an electronic furnace. The common heating rate for concrete characteristics testing is $0.5^{\circ} \mathrm{C} / \mathrm{min}$ [4] to $10^{\circ} \mathrm{C} / \mathrm{min}$ [5]. This slow heating is chosen to restrain the thermal gradients. Specimens are dried slowly, therefore the pore pressure (caused by water evaporation) does not rise up to the high values and thus the thermal damages in the concrete are minimized. Avery high heating rate can cause cracking in the concrete due to the thermal stress [5].

Real fires occurring in existing structures take place very differently from these considered models. The heating rate during a fire in buildings has been studied e.g. the research [6], refers to an experiments in Ostrava, where a compartment in the three-storey steel frame building was exposed to fire before demolition. The wooden cribs were placed into eight piles and created the fire load density per unite area of $1039 \mathrm{MJ}^{-1} \mathrm{~m}^{-2}$ (which represents the fire load of $58.5 \mathrm{kgm}^{-2}$ ). Gas temperature conditions within the fire test are shown in in Fig. 1. Primarily there are shown the records of thermocouples TG1 to TG4, they were located $0.3 \mathrm{~m}$ below the ceiling to measure gas temperature in fire compartment in Fig. 1. Thermocouples TG5 and TG6 were placed in front of the fire compartment $(0.5$ and $1 \mathrm{~m}$ from the front wall). Maximum temperature $1050{ }^{\circ} \mathrm{C}$ was reached after 62 minutes from an ignition of the wood fuel. The research pointed out to the rapid growth in the early stage of fire when the maximum gas temperature rises up to $550{ }^{\circ} \mathrm{C}$ in approximately 8 minutes [6].

An equivalent experiment was conducted in a compartment on the 8-storey steelconcrete composite frame building at the Cardington laboratory during the Building Research Establishment and large-scale fire test. Measured temperatures are depicted in Fig. 2. There is compared temperatures meassured in the comparement with the predicted temperature according to the parametric curve presented in Eurocode 1, Annex A. Despite the more moderate temperature increase after triggering a fire, the maximum temperature of gas reached $1108{ }^{\circ} \mathrm{C}$ and was achieved already in 54 minutes [7]. 


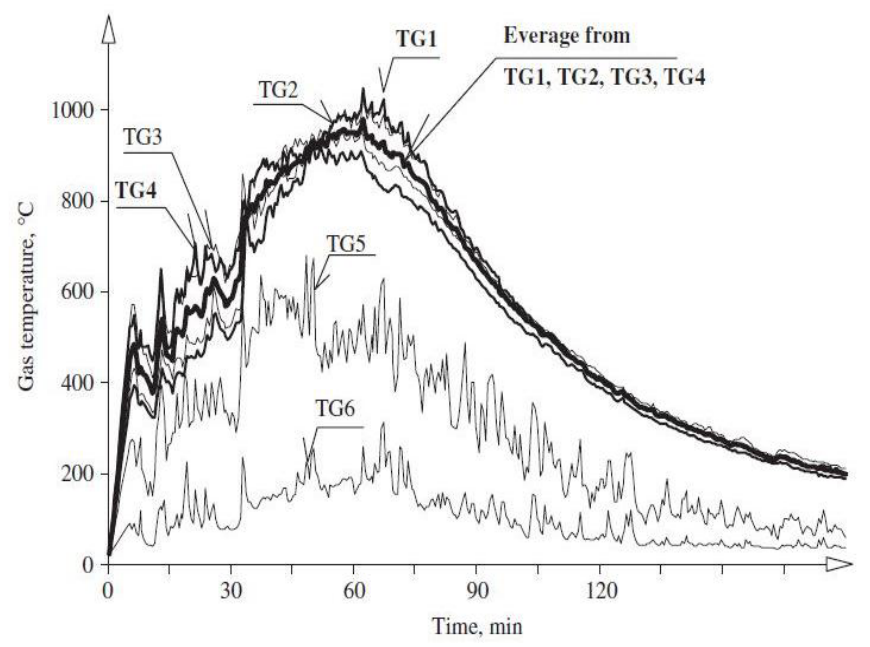

Fig. 1. Measured gas temperatures in the experimental fire compartment (Ostrava) [6].

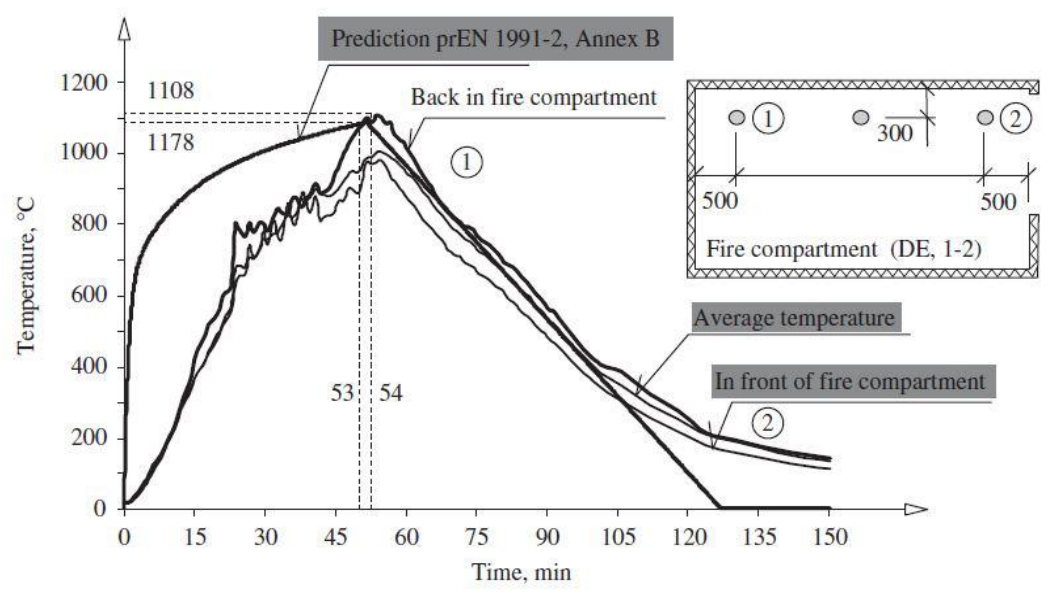

Fig. 2. Measured gas temperature in the experimental fire compartment (Cardington) [7].

According to the previously mentioned experimental results the most realistic heating rate was chosen for realization of this experiment. The fire tests were controlled in accordance with standard temperature-time curve known as ISO 834, followed by heating to the maximum temperature level in the furnace for 60 minutes. ISO 834 curve is established by EN 1991-1-2:2002/AC:2009 as a result of many experiments determining the development of temperatures at ordinary fires conditions in the structures [2].

\section{Experiment}

The panels of nominal dimensions $150 \times 1300 \times 2300 \mathrm{~mm}$ prepared from commonly used structural concrete of strength class $\mathrm{C} 30 / 37$ were tested to determine the properties of concrete after the experimental simulation of real fires.

There were casted 5 panels in total for fire tests at 550, 600, 800 and $1000{ }^{\circ} \mathrm{C}$ and one reference panel without heating. The panels were reinforced by reinforcing mesh on the 
bottom face. Total of 10 thermocouples (type K) was placed into each plate for temperature measurement during thermal tests. Thermocouples were positioned along the height of the three sections of the panels so that can be recorded temperatures on the heated and the unheated surface of the plate and in the middle of the panel thickness. Moreover, the midspan cross-section temperatures were controlled also at the one quarter of the height of the panel thickness from the bottom (heated) side of panel.

The panels were thermally loaded by using gas furnace for studying of building materials and construction elements at high temperatures in AdMaS Research Centre, see the photo in Fig. 3. The furnace chamber is heated by two massive gas burners placed diagonally on the shorter sides of the furnace. The aim of research was to simulate the load acting on the concrete elements in the conventional building construction, therefore, the material was heated according to the standard temperature-time curve ISO 834 up to the required nominal temperatures $550,600,800$ and $1000{ }^{\circ} \mathrm{C}$, after achieving the nominal temperature were maintained for 60 minutes. Then the panels were allowed to cool to ambient temperature. The real history of gas temperature in the furnace during experiment is illustrated by the temperature-time curves shown in Fig. 4. Concretes were loaded at 5 months of age, which meets the requirements for minimum age specified in Recommendation of RILEM TC 129-MHT [8].

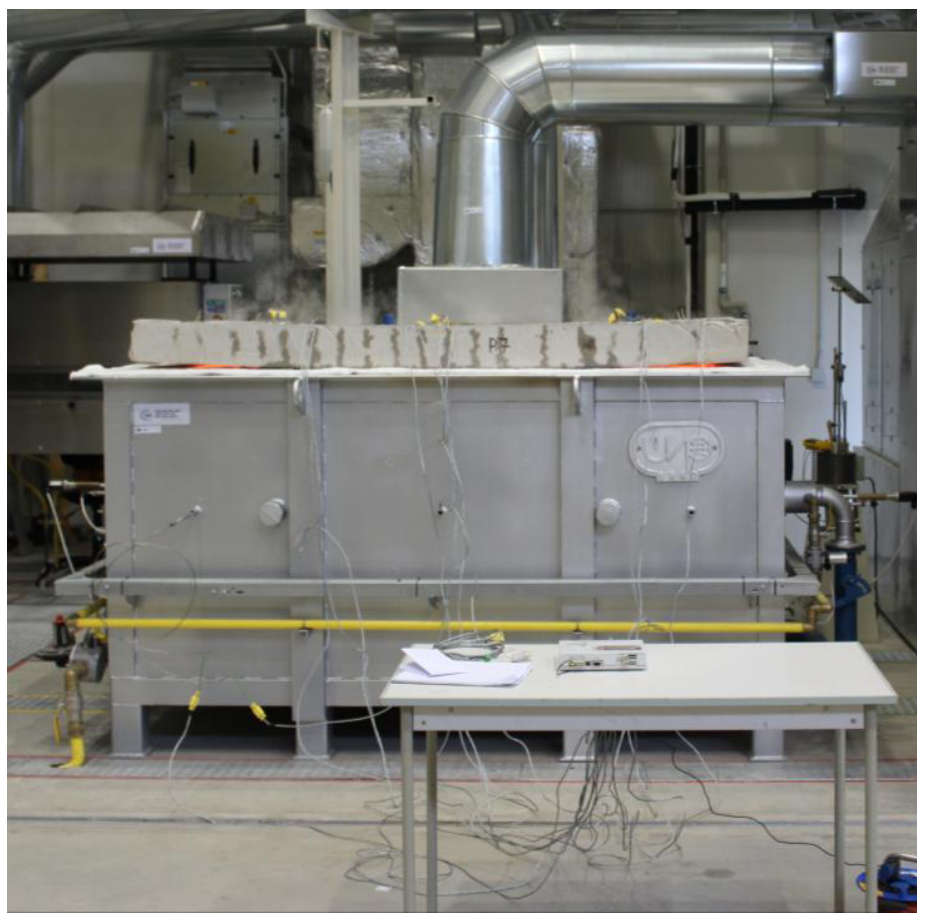

Fig. 3. Gas furnace for fire testing of the structural elements at AdMaS Centre during heating of panel P7 (maximal temperature $1000^{\circ} \mathrm{C}$ ). 


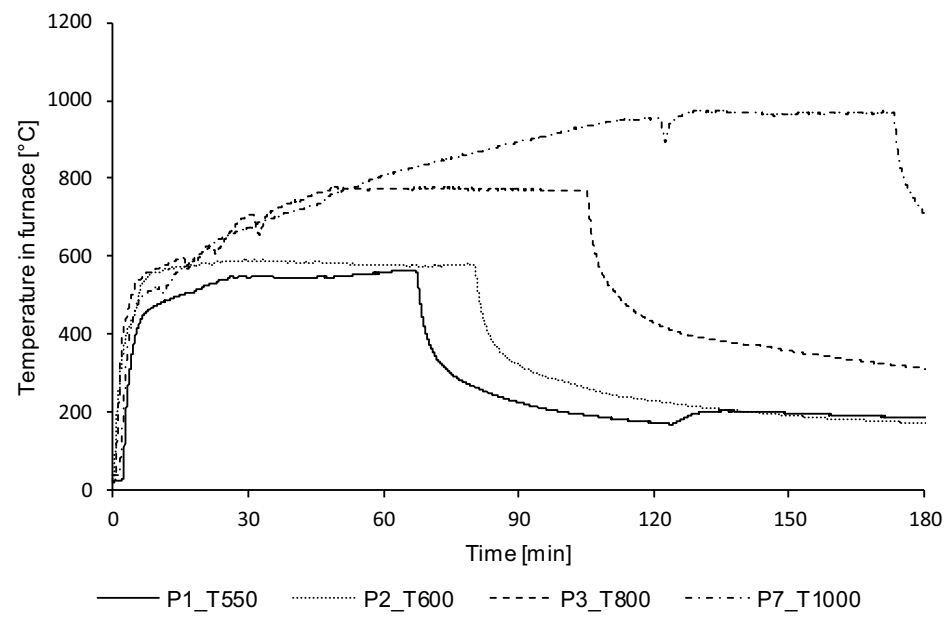

Fig. 4. Selected temperature-time curves measured in furnace during experiments carried out in AdMaS Centre.

Samples for testing were taken out by core drilling after cooling. Six cores (cylinders) of $100 \mathrm{~mm}$ diameters were got from each panel. Thereafter the cores were shortened to the $100 \mathrm{~mm}$ length (the larger thickness of material was removed from the side without thermal loading to determine the most unfavourable result). The specimens were tested for the compressive strength and the splitting tensile strength in accordance with the procedures specified in EN 12390-3:2009 [9] and EN 12390-6:2009 [10]. Furthermore, for these panels exposed to high temperatures were determined basic fracture parameters by means of evaluation of pilot fracture tests of cylindrical specimens with an initial stress concentrator in the form of a chevron notch and subsequently tested in three-point bending test, see more in [11].

\section{Results}

The values of compressive strength and splitting tensile strength of concrete exposed to the elevated temperatures according to the temperature curve of ISO 834 prolonged by the maximum temperature maintaining for one hour were determined by evaluating the experiments.

Reference specimens without temperature exposition reached a mean compressive strength $54.0 \mathrm{MPa}$ with a coefficient of variation $4.4 \%$. After thermal subjection was noticed a reduction of concrete strength characteristics, the results are shown below. The heating up to $1000{ }^{\circ} \mathrm{C}$ reduced the strength to $66 \%$. Especially, a significant increase in the variation of the compressive strength of the average values for specimens, the values exceed the $13 \%$ after heating to 600 and $800{ }^{\circ} \mathrm{C}$. Results of compressive strength tests are shown in Fig. 5 and in Table 1. 


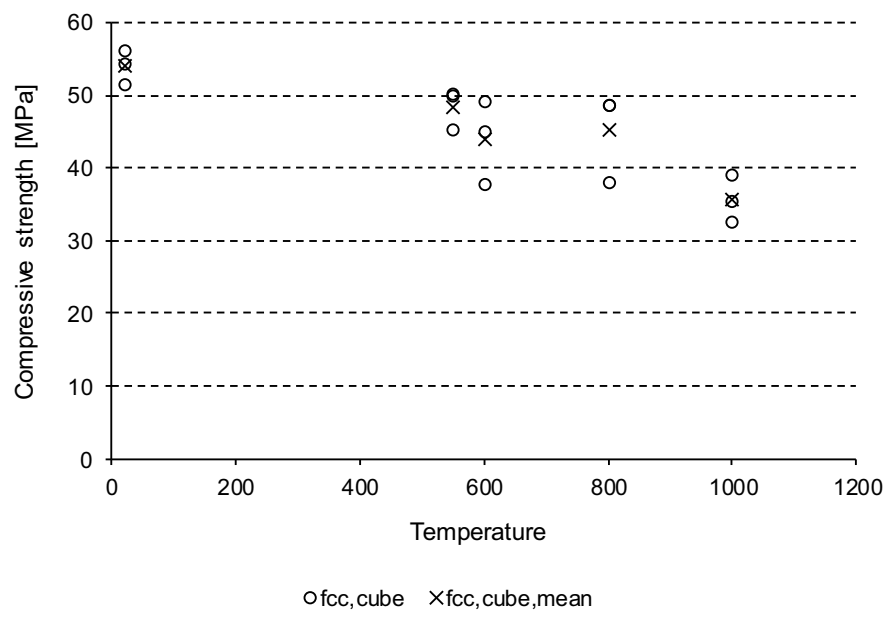

Fig. 5. Results of compressive strength tests of concrete exposed to elevated temperatures according to temperature curve ISO 834 .

Table 1. Compressive strength (and bulk density) of concrete exposed to elevated temperatures.

\begin{tabular}{|c|c|c|c|c|c|}
\hline specimen & $\begin{array}{c}\text { gas temperature } \\
{\left[{ }^{\circ} \mathrm{C}\right]}\end{array}$ & $\begin{array}{c}\rho \\
{\left[\mathrm{kg} \cdot \mathrm{m}^{-3}\right]}\end{array}$ & $\begin{array}{c}\text { fcc,cube } \\
{[\mathrm{MPa}]}\end{array}$ & $\begin{array}{c}\text { fcc,cube,mean } \\
{[\mathrm{MPa}]}\end{array}$ & $\begin{array}{c}\text { coefficient } \\
\text { of variation [\%] }\end{array}$ \\
\hline P4_C5 & \multirow{3}{*}{20} & 2263 & 56.1 & \multirow{3}{*}{54.0} & \multirow{3}{*}{4.4} \\
\hline P4_D4 & & 2261 & 54.4 & & \\
\hline P4_E3 & & 2254 & 51.5 & & \\
\hline $\mathrm{P} 1 \_3 \mathrm{C}$ & \multirow{3}{*}{550} & 2260 & 45.3 & \multirow{3}{*}{48.4} & \multirow{3}{*}{5.6} \\
\hline $\mathrm{P} 1 \_5 \mathrm{C}$ & & 2226 & 49.8 & & \\
\hline $\mathrm{P} 1 \_4 \mathrm{~F}$ & & 2293 & 50.1 & & \\
\hline P2_9F & \multirow{3}{*}{600} & 2255 & 37.8 & \multirow{3}{*}{44.0} & \multirow{3}{*}{13.1} \\
\hline $\mathrm{P} 2 \_7 \mathrm{CD}$ & & 2226 & 49.2 & & \\
\hline P2_9D & & 2253 & 45.0 & & \\
\hline P3_8D & \multirow{3}{*}{800} & 2211 & 38.0 & \multirow{3}{*}{45.1} & \multirow{3}{*}{13.6} \\
\hline P3_7DE & & 2230 & 48.7 & & \\
\hline P3_7FE & & 2247 & 48.7 & & \\
\hline P7_87ED & \multirow{3}{*}{1000} & 2229 & 39.0 & \multirow{3}{*}{35.7} & \multirow{3}{*}{9.1} \\
\hline P7_87E & & 2206 & 32.6 & & \\
\hline P7_9E & & 2197 & 35.5 & & \\
\hline
\end{tabular}

The splitting tensile strength results of unheated specimens reached a mean value 3.3 $\mathrm{MPa}$ with a coefficient of variation about $7 \%$. Specimens with temperature loading up to $1000{ }^{\circ} \mathrm{C}$ decrease the strength to $65 \%$. There were remarkable changes in the variation coefficient, it is about $12-23 \%$ for exposed material. Results of splitting tensile strength tests are shown in Fig. 6 and in Table 2. 


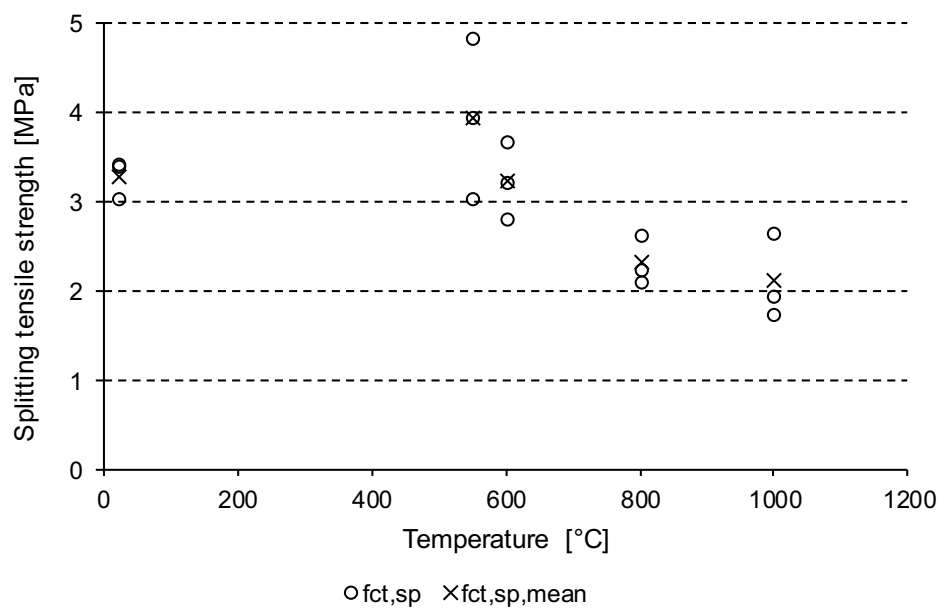

Fig. 6. Results of splitting tensile strength tests of concrete exposed to elevated temperatures according to temperature-time curve ISO 834.

Table 2. Tensile splitting strength (and bulk density) of concrete exposed to elevated temperatures.

\begin{tabular}{|c|c|c|c|c|c|}
\hline specimen & $\begin{array}{c}\text { gas temperature } \\
{\left[{ }^{\circ} \mathrm{C}\right]}\end{array}$ & $\begin{array}{c}\rho \\
{\left[\mathrm{kg} \cdot \mathrm{m}^{-3}\right]}\end{array}$ & $\begin{array}{c}\text { fct,sp } \\
{[\mathrm{MPa}]}\end{array}$ & $\begin{array}{c}\text { fct,sp,mean } \\
{[\mathrm{MPa}]}\end{array}$ & $\begin{array}{c}\text { coefficient } \\
\text { of variation [\%] }\end{array}$ \\
\hline P4 3B & \multirow{3}{*}{20} & 2305 & 3.41 & \multirow{3}{*}{3.28} & \multirow{3}{*}{6.8} \\
\hline P4_6B & & 2472 & 3.40 & & \\
\hline P4_6D & & 2265 & 3.02 & & \\
\hline P1_5D & \multirow{3}{*}{550} & 2263 & 3.02 & \multirow{3}{*}{3.93} & \multirow{3}{*}{23.1} \\
\hline P1_3D & & 2272 & 3.93 & & \\
\hline P1_5E & & 2292 & 4.83 & & \\
\hline P2 7DE & \multirow{3}{*}{600} & 2248 & 2.80 & \multirow{3}{*}{3.22} & \multirow{3}{*}{13.4} \\
\hline P2 9C & & 2246 & 3.66 & & \\
\hline $\mathrm{P} 2$ 7FE & & 2122 & 3.21 & & \\
\hline P3 7D & \multirow{3}{*}{800} & 2222 & 2.09 & \multirow{3}{*}{2.31} & \multirow{3}{*}{11.7} \\
\hline P3_7CD & & 2192 & 2.61 & & \\
\hline P3_9D & & 2211 & 2.23 & & \\
\hline P7 8D & \multirow{3}{*}{1000} & 2226 & 2.64 & \multirow{3}{*}{2.10} & \multirow{3}{*}{22.7} \\
\hline P7 $=87 \mathrm{CD}$ & & 2232 & 1.94 & & \\
\hline P7_10D & & 2260 & 1.73 & & \\
\hline
\end{tabular}

\section{Conclusion}

The outcomes of this article are compressive and splitting tensile strengths of concrete after high temperature exposition according to standard temperature-time curve ISO 834. It corresponds to the heating rate in real fires in structures. Rapid temperature increment causes development of cracks in concrete. The values of strength characteristics were affected by this phenomenon: compared to the reference concrete specimens, the maximum decrease was about $35 \%$. Increase of variation coefficient was observed in both cases of strengths, significantly in values of splitting tensile strength. Knowledge of compressive and splitting tensile strength values determined above method are suitable for use in practice to assessment of concrete structures damaged by fire. 
This outcome has been achieved with the support of the project No. LO1408 "AdMaS UP Advanced Materials, Structures and Technologies" supported by Ministry of Education, Youth and Sports under the „National Sustainability Programme I”.

\section{References}

1. EN 1990:2002, Eurocode: Basis of structural design (CEN, Brussels, 2002)

2. EN 1991-1-2:2002/AC:2009, Eurocode 1: Actions on structures - Part 1-2: General actions - Actions on structures exposed to fire (CEN, Brussels, 2002)

3. I. Hager, Bull Pol Acad Sci-Te 61, 1 (2013)

4. K. Krzemień, I. Hager, Constr Build Mater 96, 155-163 (2015)

5. R. Felicetti, F. Lo Monte, P. Pimisenta, F. Meftah, MATEC web conf. 6 (2013)

6. F. Wald, J. Chlouba, A. Uhlír, P. Kallerová, M. Štujbetová, Fire Safety J. 44 (2009)

7. F. Wald, L. Simoñes Da Silva, D. B. Moore, T. Lennon, M. Chladná, A. Santiago, M. Beneš, L. Borges, Fire Safety J. 41 (2006)

8. RILEM TC 129-MHT, Mater Struct, 33, 224-228 (1997)

9. EN 12390-3:2009, Testing hardened concrete - Part 3: Compressive strength of test specimens (CEN, Brussels, 2009)

10. EN 12390- 6:2009, Testing hardened concrete - Part 6: Tensile splitting strength of test specimens (CEN, Brussels, 2009)

11. H. Šimonová, P. Halfar, I. Rozsypalová, P. Daněk, Z. Keršner, MATEC web conf. (to be published) 